\title{
Protein dynamics measurements by 3D HNCO based NMR experiments
}

\author{
Youlin Xia ${ }^{\text {a }}$, Kong Hung Sze ${ }^{\mathrm{a}}$, Ning Li ${ }^{\mathrm{b}}$, Pang Chui Shaw ${ }^{\mathrm{c}}$ and Guang Zhu ${ }^{\mathrm{a}, *}$ \\ ${ }^{a}$ Department of Biochemistry, The Hong Kong University of Science and Technology, Kowloon, Hong \\ Kong, PR China \\ ${ }^{\mathrm{b}}$ Department of Biology, The Hong Kong University of Science and Technology, Kowloon, Hong Kong, \\ PR China \\ ${ }^{\mathrm{c}}$ Department of Biochemistry, The Chinese University of Hong Kong, Shatin, Hong Kong, PR China
}

\begin{abstract}
Protein dynamics can be characterized by relaxation parameters obtained from traditional 2D HSQC based NMR experiments. This approach is hampered when applied to proteins with severe spectral overlap. In the present work, several novel 3D TROSY-HNCO and 3D HSQC-HNCO based NMR experiments were applied for measuring ${ }^{15} \mathrm{~N} T_{1}, T_{2}$ and ${ }^{1} \mathrm{H}-{ }^{15} \mathrm{~N}$ NOE with improved spectral dispersion by introducing a third ${ }^{13} \mathrm{C}$ dimension. The number of phase cycling steps in these $3 \mathrm{D}$ pulse sequences was restricted to two in order to minimize the time required to perform the dynamics measurements. For a uniformly $100 \%{ }^{15} \mathrm{~N}, 100 \%{ }^{13} \mathrm{C}$, and $70 \%{ }^{2} \mathrm{H}$-labelled trichosanthin sample $(\sim 27 \mathrm{kDa}, 1.0 \mathrm{mM})$ at $30{ }^{\circ} \mathrm{C}$, the sensitivity of 3D TROSY-HNCO based experiment was, on the average, enhanced by 72\% compared to that of 3D HSQC-HNCO based experiments. However, the 3D HSQC-HNCO based experiments should be more effective for non-deuterated proteins with smaller molecular weights and seriously overlapped 2D HSQC spectra. Results from the 3D TROSY-HNCO and 3D HSQCHNCO based experiments were in good agreement with those obtained from traditional 2D HSQC based experiments.
\end{abstract}

Keywords: Dynamics measurement, TROSY, HNCO, HSQC

\section{Introduction}

Complete understanding of protein function and folding requires the detailed study of protein dynamics [1-8]. In addition, protein backbone ${ }^{15} \mathrm{~N}$ relaxation rates can be used as a tool for the diagnosis of structure quality [9]. These studies include measurements of the longitudinal relaxation time $\left(T_{1}\right)$, transverse relaxation time $\left(T_{2}\right)$ of backbone ${ }^{15} \mathrm{~N}$ nuclei and the heteronuclear NOE between backbone ${ }^{15} \mathrm{~N}$ and the attached ${ }^{1} \mathrm{H}$ by well established NMR techniques based on the traditional 2D HSQC experiment [10]. These parameters are then used to obtain overall correlation time $\left(\tau_{\mathrm{c}}\right)$, effective correlation times $\left(\tau_{\mathrm{e}}\right)$ for internal motions and generalized order parameters $\left(S^{2}\right)$ to characterize protein dynamics based on a model free approach [11,12]. The $S^{2}$ factors are also essential for the proper use of the residual dipolar couplings for structure calculation [13-15]. Therefore, the measurement of these parameters is very important, not only for characterizing protein dynamics but also for the refinement of protein structures.

TROSY [16-22] based 2D experiments [23] can enhance sensitivity and improve resolution in protein dynamics studies compared with the HSQC-based 2D experiments [10]. Hence, these experiments represent a significant advancement in the ability to elucidate internal motions in large proteins. However, as the molecular weight of proteins under NMR investigation increases, spectral overlap becomes more severe in 2D TROSY spectra, and hampers accurate analysis of the protein dynamics. An apparent solution

\footnotetext{
*Corresponding author. Fax: +852 2358 1552; E-mail: gzhu@ust.hk.
} 
is to expand these 2D TROSY-based experiments to 3D TROSY-based experiments. In parallel, the 3D HSQC-HNCO based experiments should be effective for non-deuterated proteins with smaller molecular weights and seriously overlapped 2D HSQC spectra. In the present work, several novel 3D TROSYHNCO and 3D HSQC-HNCO based pulse sequences are proposed for measuring ${ }^{15} \mathrm{~N} T_{1}$ and $T_{2}$, and ${ }^{1} \mathrm{H}_{-}{ }^{15} \mathrm{~N}$ NOE in order to overcome spectral overlapping problems in the corresponding $2 \mathrm{D}$ spectra.

\section{Theory}

Figure 1 depicts the pulse sequences (Fig. 1(A): T1-TROSY-HNCO; Fig. 1(B): T2-TROSY-HNCO; Fig. 1(C): NOE-TROSY-HNCO; Fig. 1(D): T1-HSQC-HNCO) used for the 3D TROSY-HNCO and 3D HSQC-HNCO based NMR experiments. In this work, conventional HNCO is termed HSQC-HNCO in order to distinguish it from TROSY-HNCO. Figure 1(B) and (C) combining with the section in the dashed line box of Fig. 1(D) form the 3D T2-HSQC-HNCO and the 3D NOE-HSQC-HNCO pulse sequences, respectively.

HNCO is the most sensitive triple resonance experiment, therefore TROSY-HNCO was selected and modified to measure the dynamics parameters of larger deuterated proteins, and HSQC-HNCO was modified for non-deuterated proteins with smaller molecular weights and seriously overlapped 2D HSQC spectra. Since about 12 to18 3D spectra must be recorded for the measurement of $T_{1}, T_{2}$, and NOE values, a minimal number of phase cycling steps is necessary to finish all these 3D NMR experiments in a reasonable time. For general heteronuclear NMR experiments, a phase cycling scheme with a minimum of two steps is necessary in order to perform isotope filtering [24] and remove unlabelled solvent peaks, therefore a two-step scheme was adapted for the proposed pulse sequences. The two-step phase cycling scheme in Fig. 1 can be realized by setting $\varphi_{1}, \varphi_{2}$, or $\varphi_{3}$ as $(x,-x)$ and $\varphi_{\mathrm{r}}$ as $(x,-x)$, if only to perform isotope filtering or to eliminate those unlabelled solvent peaks. Furthermore, applying two-step phase cycling scheme on $\varphi_{1}$ also has the benefit of removing the contribution to the observed signal from the steady-state value of the ${ }^{15} \mathrm{~N}$ magnetization during the period of relaxation delay $T$ in the T1-TROSYHNCO (Fig. 1(A)) and T1-HSQC-HNCO (Fig. 1(D)) experiments [25,26]. Hence, the two-step phase cycling scheme of $\varphi_{1}$ and $\varphi_{\mathrm{r}}$ was applied in the proposed pulse sequences in Fig. 1.

The resonance peaks of ${ }^{1} \mathrm{H}_{-}{ }^{15} \mathrm{~N}-{ }^{12} \mathrm{C}^{\prime}$ moieties are present in the plane of $\omega_{\mathrm{CO}}=0$, i.e., become so-called axial peaks, if $\varphi_{2}$ is not phase-cycled independently for ${ }^{13} \mathrm{C}$ isotope filtering. However, these artifacts are moved onto two terminal planes in the ${ }^{13} \mathrm{C}^{\prime}$ frequency dimensions of the 3D TROSY-HNCO and 3D HSQC-HNCO spectra by inverting $\varphi_{2}$ and $\varphi_{\mathrm{r}}$ for every second $t_{1}$, i.e., States-TPPI method [27].

The coherence transfer in the proposed pulse sequences can be explained simply as follows. In the T1-TROSY-HNCO pulse sequence (Fig. 1(A)), ${ }^{1} \mathrm{H}$ longitudinal magnetization $\left(H_{z}\right)$ is transferred to ${ }^{15} \mathrm{~N}$ $\left(N_{z}\right)$ through the refocused INEPT. In the period of relaxation delay $T,{ }^{15} \mathrm{~N}$ longitudinal magnetization is partially recovered to $M_{z}(T)$. And the following is a 3D TROSY-HNCO sequence. In the T2-TROSYHNCO pulse sequence (Fig. 1(B)), ${ }^{15} \mathrm{~N}$ inphase transverse magnetization is allowed to decay during relaxation delay $T$ due to spin-spin relaxation, and the CPMG portion [28,29] can remove the influence of field inhomogeneity and $180^{\circ}$ pulse imperfections. For ${ }^{1} \mathrm{H}-{ }^{15} \mathrm{~N}$ NOE measurement (Fig. 1(C)), there are two spectra to be acquired, which correspond to NOE and NONOE experiments. In the NOE experiment, ${ }^{1} \mathrm{H}$ magnetization in steady-state is saturated by a series of $120^{\circ}$ pulses and partial ${ }^{1} \mathrm{H}$ magnetization is transferred to ${ }^{15} \mathrm{~N}$ due to dipole-dipole interaction between ${ }^{1} \mathrm{H}$ and ${ }^{15} \mathrm{~N}$. The co-addition of magnetization transferred from ${ }^{1} \mathrm{H}$ and steady-state magnetization of ${ }^{15} \mathrm{~N}$ then becomes the initial magnetization of the following 3D TROSY-HNCO. In the NONOE experiment, the saturating irradiation 
(A)

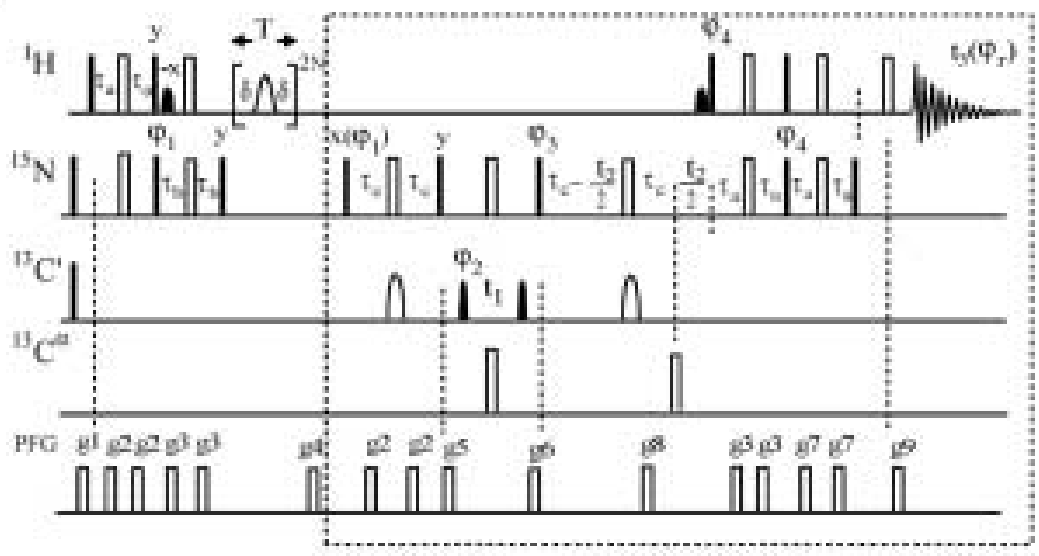

(B)

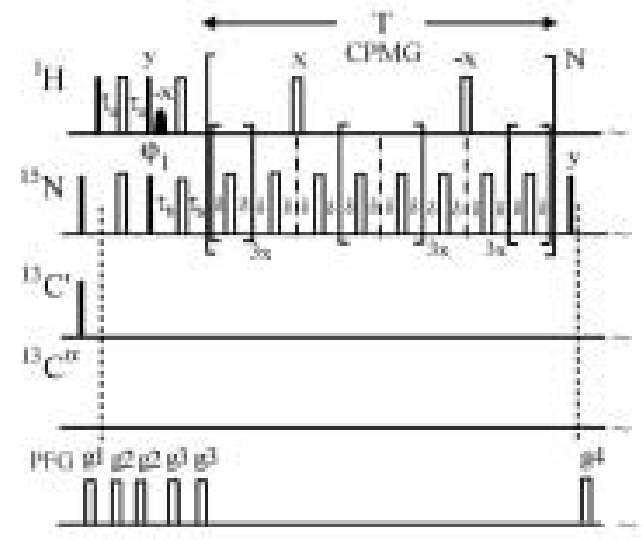

(C)

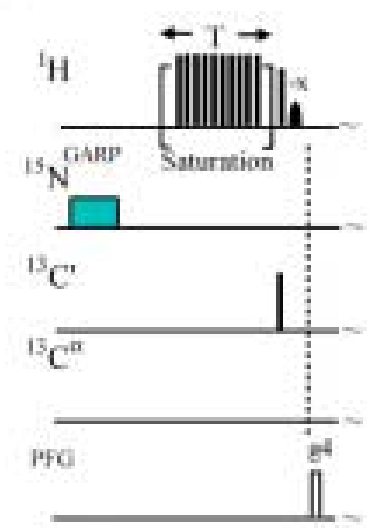

(D)

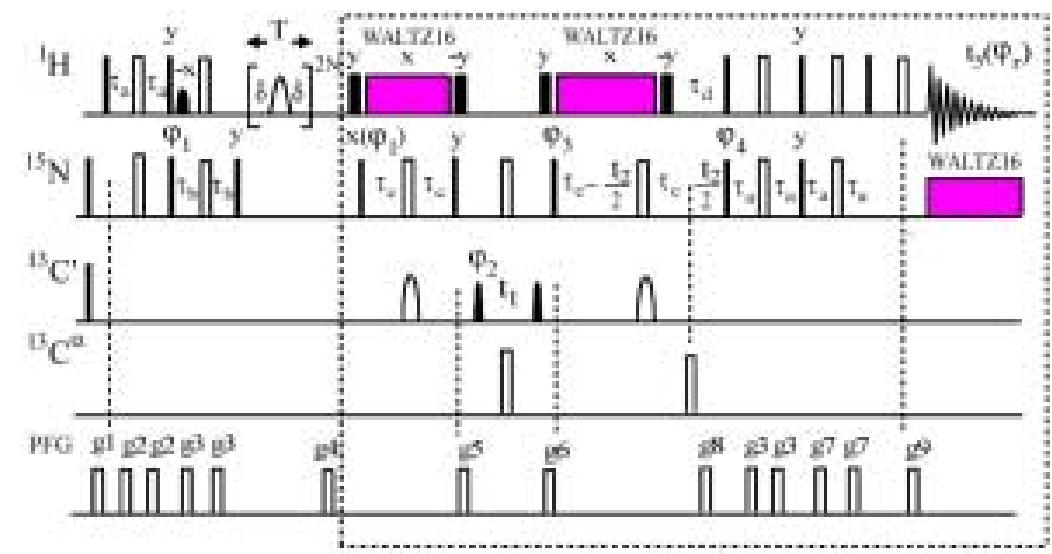

Fig. 1. Pulse sequences for the measurement of ${ }^{15} \mathrm{~N} T_{1}$ ((A): T1-TROSY-HNCO; D: T1-HSQC-HNCO), ${ }^{15} \mathrm{~N} T_{2}$ ((B): T2-TROSY-HNCO), and ${ }^{1} \mathrm{H}_{-}{ }^{15} \mathrm{~N}$ NOE ((C): NOE-TROSY-HNCO). The sections not plotted in (B) and (C) are the same as that in the dashed line box of (A). (B) and (C) combining with the section in dashed line box of (D) forms the 3D 
1T2-HSQC-HNCO and NOE-HSQC-HNCO pulse sequences, respectively. For the 3D NOE-HSQC-HNCO pulse sequence, the GARP decoupling before ${ }^{1} \mathrm{H}$ saturation should be removed. In all sequences, filled bars and open bars represent $90^{\circ}$ and $180^{\circ}$ pulses, respectively. Filled shaped pulses are $1.1 \mathrm{~ms}$ sinc-modulated rectangular $90^{\circ}$ pulses to selectively excite the water resonance. Default phases are $x .{ }^{1} \mathrm{H},{ }^{15} \mathrm{~N}$, and ${ }^{13} \mathrm{C}^{\prime}$ carrier frequencies are centered at $4.7,120$, and $174 \mathrm{ppm}$, respectively. ${ }^{13} \mathrm{C}^{\prime} 90^{\circ}$ (filled shaped pulse) and $180^{\circ}$ (open shaped pulse) pulses are sinc-modulated rectangular pulses with pulse widths of 71.2 and $64.4 \mu \mathrm{s}$, respectively. ${ }^{13} \mathrm{C}^{\alpha} 180^{\circ}$ pulses are phase-modulated rectangular pulses, whose pulse widths, $39 \mu \mathrm{s}$, satisfy the relation of $\sqrt{3 / \Delta}$, where $\Delta$ is the separation between the centers of the ${ }^{13} \mathrm{C}^{\alpha}$ and ${ }^{13} \mathrm{C}^{\prime}$ chemical shift regions. $\tau_{\mathrm{a}}=2.50 \mathrm{~ms}$, $\tau_{\mathrm{b}}=1 /\left(4^{1} \mathrm{~J}_{\mathrm{NH}}\right) \approx 2.70 \mathrm{~ms}, \tau_{\mathrm{c}}=15 \mathrm{~ms}$, and $\tau_{\mathrm{d}}=5.4 \mathrm{~ms}$. For the three experiments based on 3D TROSY-HNCO, phase cycling is as follows: $\varphi_{1}=(x,-x) ; \varphi_{2}=(x) ; \varphi_{3}=(y) ; \varphi_{4}=(y) ; \varphi_{\mathrm{r}}=(x,-x)$. For the three experiments based on the 3D HSQC-HNCO, phase cycling is the same as that of the three experiments based on the 3D TROSY-HNCO, except that $\varphi_{4}=(-x)$. For the $90^{\circ}$ pulse labeled $x\left(\varphi_{1}\right)$ in (A) and (D), its phase is $x$ for measuring T1 and T2, $\varphi_{1}$ for measuring NOE. Quadrature components in $t_{1}$ were acquired through altering $\varphi_{2}$ in a states-TPPI manner; echo/anti-echo selections during $t_{2}$ were done by inverting the sign of $\varphi_{4}$ and gradient g8. Axial peaks in the F1 and F2 dimensions were removed by inverting $\left(\varphi_{2}, \varphi_{\mathrm{r}}\right)$ and $\left(\varphi_{3}, \varphi_{\mathrm{r}}\right)$ for every second $t_{1}$ and $t_{2}$, respectively. The durations and strengths of the gradients are $\mathrm{g} 1=(0.4 \mathrm{~ms}$, $15 \mathrm{G} / \mathrm{cm}) ; \mathrm{g} 2=(0.4 \mathrm{~ms}, 5 \mathrm{G} / \mathrm{cm}) ; \mathrm{g} 3=(0.4 \mathrm{~ms}, 10 \mathrm{G} / \mathrm{cm}) ; \mathrm{g} 4=(0.4 \mathrm{~ms}, 10 \mathrm{G} / \mathrm{cm}) ; \mathrm{g} 5=(0.5 \mathrm{~ms}, 15 \mathrm{G} / \mathrm{cm}) ; \mathrm{g} 6=(0.5 \mathrm{~ms}$, $10 \mathrm{G} / \mathrm{cm}) ; \mathrm{g} 7=(0.4 \mathrm{~ms}, 8 \mathrm{G} / \mathrm{cm}) ; \mathrm{g} 8=(1.0 \mathrm{~ms}, 15 \mathrm{G} / \mathrm{cm}) ; \mathrm{g} 9=(0.1 \mathrm{~ms}, 15 \mathrm{G} / \mathrm{cm})$. In the T1-TROSY-HNCO sequence (A) and the T1-HSQC-HNCO sequence (D) an even number of shaped pulses, $333 \mu$ s cosine-modulated rectangular $180^{\circ}$ pulses [40] with excitation maxima positioned $4 \mathrm{ppm}$ from the carrier (on water), were applied every $5 \mathrm{~ms}(\delta=2.5 \mathrm{~ms}$ ) during the recovery time $T$. The experimental recovery delay was $0.8 \mathrm{~s}$. In T2-TROSY-HNCO (B), $\delta=0.4 \mathrm{~ms}$, and the experimental recovery delay is $0.8 \mathrm{~s}$. In order to reduce heating effects during the CPMG portion [28,29], the rf power of the ${ }^{15} \mathrm{~N} 180^{\circ}$ pulse in the CPMG section was decreased by $3 \mathrm{~dB}$ compared with the full rf power in ${ }^{15} \mathrm{~N}$ channel. In NOE-TROSY-HNCO (C), ${ }^{1} \mathrm{H}$ saturation was achieved by the applying $120^{\circ}$ pulses [41] spaced at $5 \mathrm{~ms}$ intervals for $3 \mathrm{~s}$ prior to the first ${ }^{15} \mathrm{~N}$ pulse. The rf power of proton channel in the saturation period was reduced by $6 \mathrm{~dB}$ to reduce the heating effect. An overall delay between scans of $5 \mathrm{~s}$ was employed in both the NOE and NONOE experiments.

period is replaced by a delay of the same time interval, therefore only the steady-state magnetization of ${ }^{15} \mathrm{~N}$ contributes to the initial magnetization of the following 3D TROSY-HNCO.

In order to realize TROSY, the slowly relaxing component of the doublet should be chosen. There are at present two approaches to select the slowly relaxing component: one is through independent two-step phase cycling, such as $\varphi_{3}=(y, x)$ and $\varphi_{\mathrm{r}}=(y, x)$ [23]; the other is through a selective gradient magnetic field [22]. Due to limited time, the latter approach was chosen for the proposed pulse sequences.

Regarding the 3D HSQC-HNCO based pulse sequences, the T1, T2, and NOE sections before HNCO are the same as those of 3D TROSY-HNCO based pulse sequences, while the HNCO section following is modified from conventional HNCO [24].

\section{Experimental and results}

To demonstrate the effectiveness of the proposed techniques, they were applied to a uniformly $100 \%$ ${ }^{15} \mathrm{~N}, 100 \%{ }^{13} \mathrm{C}$, and $70 \%{ }^{2} \mathrm{H}$-labelled trichosanthin sample $\left(\sim 27 \mathrm{kDa}, 1.0 \mathrm{mM}\right.$ in $20 \mathrm{mM} \mathrm{Na}_{2} \mathrm{HPO}_{4}$, pH 6.8, 95\% $\mathrm{H}_{2} \mathrm{O} / 5 \% \mathrm{D}_{2} \mathrm{O}$ ) at $30^{\circ} \mathrm{C}$ using Varian Inova $750 \mathrm{MHz}$ and $500 \mathrm{MHz}$ NMR spectrometers. If without special indication, data were acquired on the $750 \mathrm{MHz}$ NMR spectrometer.

In order to demonstrate the difference in sensitivity between the 3D T1-TROSY-HNCO and 3D T1HSQC-HNCO experiments, two spectra were recorded with identical acquisition and processing parameters. Data matrices in the time domain were composed of $42^{*} \times 60^{*} \times 1024^{*}$ points $(*$ signifies complex points), with a spectral width of $2400 \mathrm{~Hz} \times 2400 \mathrm{~Hz} \times 10500 \mathrm{~Hz}$. The number of scans for each transient was 2 . Recovery delay between scans was $0.8 \mathrm{sec}, T=10.6 \mathrm{~ms}$, and the total experimental time for acquiring a 3D spectrum was 5 hours and 44 minutes. Cosine bell window functions were used to obtain the 3D spectra before Fourier transformation, which were composed of $128 \times 256 \times 1024$ points. All data was processed using the nmrPipe software package [30]. 
For the 172 well isolated peaks examined, the signal sensitivities were enhanced by $-28 \%$ to $131 \%$ [31]. On the average, the sensitivity of the former experiment was $72 \%$ greater than that of the latter at $30^{\circ} \mathrm{C}$, at which temperature the molecular tumbling time of trichosanthin is about $15 \mathrm{~ns}$. For a fully deuterated or larger protein, the TROSY effect should be even more pronounced.

For comparison, 2D TROSY- and HSQC-based dynamics experiments have also been carried out. The sensitivity of the spectrum recorded by 2D T1-TROSY [23] was, on average, enhanced by $17 \%$ [31] compared with that of a spectrum recorded by 2D T1-HSQC [10] with identical acquisition and processing parameters. Line widths were reduced, on average, by $8 \%$ and $17 \%$ in the $\mathrm{HN}$ and $\mathrm{N}$ dimensions, respectively. For all $2 \mathrm{D}$ experiments, $256^{*} \times 1024^{*}$ data matrices in the time domain were acquired with spectral widths of $2400 \mathrm{~Hz} \times 10500 \mathrm{~Hz}$. The number of scans for each transient was 8 . Recovery delay between scans was $1.0 \mathrm{sec}$. Cosine bell window functions were used to obtain the 2D spectra before Fourier transformation, which were composed of $1024 \times 2048$ points. Although the 2D TROSY spectrum had better resolution than the 2D HSQC spectrum, 2D TROSY may not be able to completely resolve the overlapping NMR resonance peaks of large proteins, which will be better resolved on a 3D spectrum (Fig. 2).

Figure 2(A) and (B) show small regions of spectra recorded using 2D T1-HSQC and 2D T1-TROSY, respectively. The 2D TROSY spectrum has better sensitivity and resolution than the 2D HSQC spectrum, however some peaks, such as peaks of no. 117 and no. 132, are not resolved even in the 2D TROSY spectrum. Two small 2D slices taken from the 3D T1-TROSY-HNCO spectrum, with CO chemical shifts

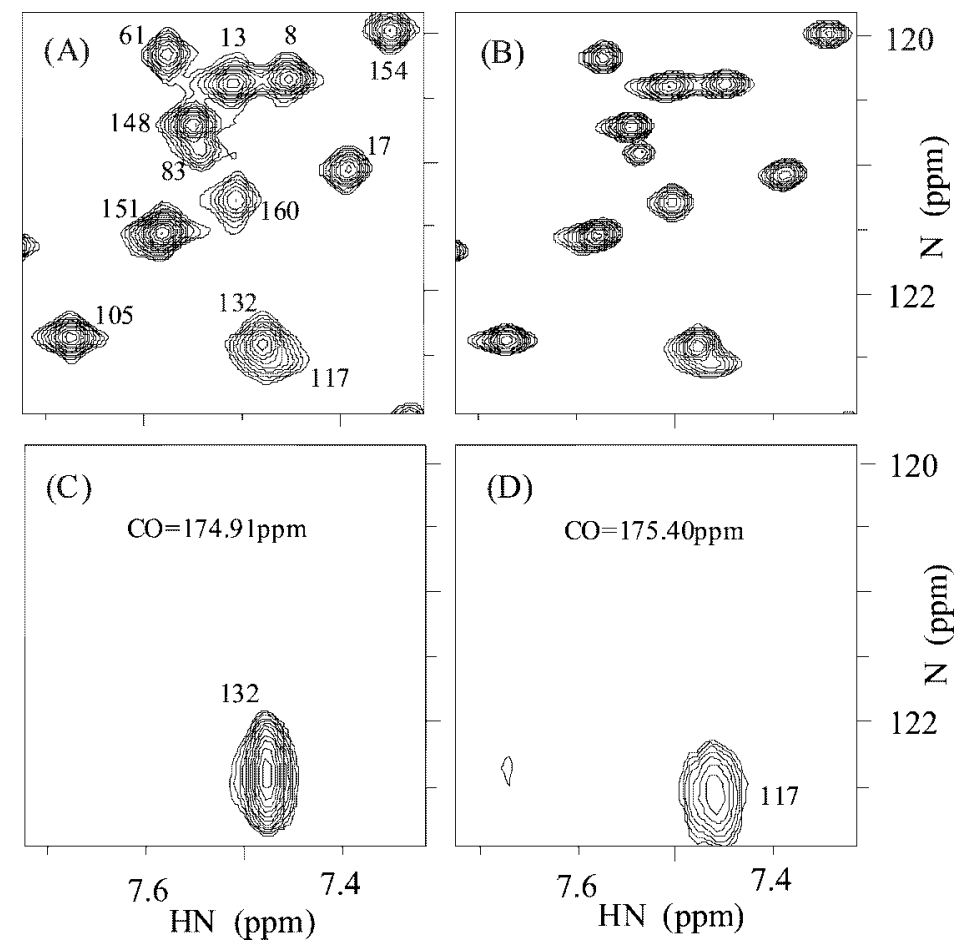

Fig. 2. Small regions of spectra recorded by 2D T1-HSQC (A) and 2D T1-TROSY (B). Small 2D slices taken from a 3D TROSY-HNCO spectrum with CO chemical shifts of $174.91 \mathrm{ppm}(\mathrm{C})$ and $175.40 \mathrm{ppm}(\mathrm{D})$. The lowest contours for spectra (A) and (B) are drawn at the same level, and they are identical for (C) and (D). Contours are spaced by a factor of 1.3. 
of $174.91 \mathrm{ppm}$ and $175.40 \mathrm{ppm}$, are shown in Fig. 2(C) and (D), respectively. Because these two peaks have different $\mathrm{CO}$ chemical shifts, they are completely resolved in the 3D TROSY-HNCO spectrum.

Two sets of $T_{1}, T_{2}$, and NOE spectra were recorded with 3D TROSY-HNCO and conventional 2D HSQC [10] to compare the results measured from 3D and 2D experiments. In all 3D T1-TROSY-HNCO, T2-TROSY-HNCO, 2D T1-HSQC and T2-HSQC experiments, acquisition and processing parameters were the same as those stated in the previous paragraphs. The $T_{1}$ values were measured from spectra recorded with eight different relaxation delays with $T=0.011,0.128,0.267,0.533,0.800,1.120,1.440$ and $1.867 \mathrm{sec}$. The $T_{2}$ values were determined from spectra recorded with relaxation delays of $T=14.1$, 28.2, 42.3, 56.4, 70.5, 84.6, 98.7 and $112.8 \mathrm{~ms}$. The total time for acquiring the eight 3D T1-TROSYHNCO and eight 3D T2-TROSY-HNCO spectra was about 80.0 and 45.5 hours, respectively. In other words, all 3D T1-TROSY-HNCO and 3D T2-TROSY-HNCO experiments could be completed within about 5 days. If only five 3D spectra were recorded for each set of $T_{1}$ and $T_{2}$ measurements [32], these experiments would be finished within 3 days.

The NOE values were determined from spectra recorded with and without a proton presaturation period of $3 \mathrm{~s}$. The number of scans was 6 and 40 for the 3D and 2D experiments, respectively. It should be noted that even when the number of scans in the 3D NOE-TROSY-HNCO and 3D NONOE-TROSYHNCO experiments was reduced to 4, there was still enough sensitivity for the accurate measurement of the NOE values (data not shown). The recovery delay between scans was $2.0 \mathrm{sec}$, and the total experimental time for acquiring a 3D NOE or NONOE spectrum was 87.5 hours (58 hours and 20 minutes when the number of scans was 4). The processing parameters for the 3D and 2D NOE and NONOE spectra were the same as those for the 3D T1-TROSY-HNCO spectra and 2D T1-HSQC spectra, respectively.

The $T_{1}$ and $T_{2}$ values were determined by fitting the measured peak intensities with a two-parameter function of the form [10]

$$
I(T)=I_{0} \exp \left(-T / T_{1,2}\right)
$$

where $I(T)$ is the intensity after relaxation delay time $T$, and $I(0)$ is the intensity at time $T=0$. Steadystate NOE values were determined from the ratios of the intensities of the peaks obtained with (NOE) and without (NONOE) proton presaturation irradiation.

The $T_{1}, T_{2}$ and NOE values measured for 172 well-separated residuals are listed in Table 1. It should be noted that the $T_{1}, T_{2}$ and NOE data for some peaks could not be obtained from the 2D HSQC-based experiments due to peak overlap. A full dynamics analysis for the complete backbone of this protein will be published elsewhere.

In order to evaluate the significance of the small differences between relaxation parameters obtained in the 3D TROSY-HNCO-based experiments and in the 2D HSQC-based experiments, a statistical analysis utilizing the Student's $T$-test $[33,34]$ was carried out on the corresponding $T_{1}, T_{2}$ and NOE data sets. The calculated significance probabilities were $0.34,0.98$ and 0.66 for the $T_{1}, T_{2}$ and NOE data, respectively. Compared with a critical probability of 0.05 at the $95 \%$ confidence level, these values clearly indicate that the relaxation parameters measured in the TROSY-HNCO based experiments were not significantly different from those obtained through the 2D HSQC based experiments. A statistical analysis of the pair-wise differences between relaxation values obtained with the two methods, gave (mean, standard deviation) values of $(-0.01,0.05),(0.000,0.002)$ and $(0.00,0.05)$ for the $T_{1}, T_{2}$ and NOE data, respectively. This shows excellent agreement between the 3D TROSY-HNCO based experiments and the corresponding 2D HSQC based experiments. 
Table 1

The measured T1, T2 and NOE values and associated standard deviations ( $\sigma_{\mathrm{i}}$, where $i=\mathrm{T} 1, \mathrm{~T} 2$ or NOE) obtained from the 3D TROSY-HNCO based experiments and their corresponding 2D HSQC experiments for some peaks

\begin{tabular}{|c|c|c|c|c|c|c|c|c|c|c|c|c|c|c|c|}
\hline \multirow[t]{2}{*}{ no. } & \multicolumn{6}{|c|}{ 3D HNCO } & \multicolumn{6}{|c|}{ 2D HSQC } & \multicolumn{3}{|c|}{ HNCO-HSQC } \\
\hline & $\mathrm{T} 1$ & $\Gamma 1$ & $\mathrm{~T} 2$ & $\mathrm{~T} 2$ & $\mathrm{DE}$ & & $\mathrm{T} 1$ & 11 & $\mathrm{~T} 2$ & $\sigma_{\mathrm{T} 2}$ & $\mathrm{DE}$ & & $\Delta \mathrm{T} 1$ & $\Delta \mathrm{T} 2$ & $\Delta \mathrm{NOE}$ \\
\hline 1 & 1.36 & & & & 1 & & 39 & & & & 88 & & & .000 & $\overline{003}$ \\
\hline 2 & 47 & & & & & & & & & & & & & .004 & 0.10 \\
\hline 3 & 29 & & & & & & & & & & & & & & 0.0 \\
\hline 4 & 10 & & & & & & & & & & & & 0.07 & & 0.00 \\
\hline 5 & 45 & & & & 70 & & & & 7 & 0.00 & .76 & 0.02 & -0.0 & 0.002 & -0.06 \\
\hline 6 & & & & & & & & & & & & & 0.05 & 02 & 0.04 \\
\hline 7 & 19 & & & & 92 & & & & 0.038 & 0.001 & & .00 & -0.04 & 0.002 & 0.06 \\
\hline 8 & & & & & & & & & & $\delta 1$ & & .02 & 0.04 & 33 & -0.08 \\
\hline 9 & 57 & 74 & 46 & 02 & & & 1.46 & & 43 & 0.001 & 91 & .02 & 0.1 & 0.003 & 0.04 \\
\hline 10 & 45 & & 15 & 1 & & & & & 43 & 01 & 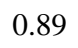 & 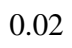 & 0.10 & 0.002 & -0.01 \\
\hline 11 & 32 & & 44 & & & & 1.37 & & 45 & 001 & & 3 & -0.05 & -0.001 & -0.02 \\
\hline 1 & & & & & & & & & & & & & & & 05 \\
\hline 13 & 8 & & 45 & 01 & & & & & 47 & 0.001 & 81 & .02 & -0.07 & -0.002 & 0.00 \\
\hline . & & & & & & & & & & & & & 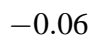 & .001 & -0.01 \\
\hline 15 & & & 50 & 2 & & & & & 46 & 0.001 & & $0 .{ }^{-}$ & 0.03 & 0.004 & 0.05 \\
\hline 1 & & & & & & & & & & & & & & & \\
\hline 17 & & & 44 & 01 & 30 & & & & 0.044 & 0.000 & 38 & 2 & -0.01 & 0.000 & -0.08 \\
\hline 1 & & & & & & & & & & & & & & & 0.00 \\
\hline 19 & 39 & 0 & 42 & 2 & 0.84 & & & & & 0.001 & 89 & 0. & 0.05 & -0.001 & -0.05 \\
\hline 20 & 9 & 0 & 10 & & & & 40 & & 46 & 1 & & 4 & 1 & 6 & -0.06 \\
\hline 2 & 36 & 0.03 & 044 & 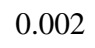 & 8 & & 1 & 1 & 44 & 0.000 & 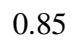 & 0. & -0 & 0.000 & -0.07 \\
\hline 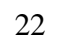 & 0 & ) & & 1 & & & & & 44 & 01 & & 4 & -0.02 & 01 & 0.00 \\
\hline 2 & 6 & & 50 & 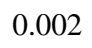 & & & & & & 1 & & & 0.08 & 04 & 0.02 \\
\hline 2 & 8 & 0 & 41 & 1 & & & 3 & 1 & 43 & 01 & 0 & 3 & -0.05 & 02 & 0.04 \\
\hline 2 & & & & & & & & & & & & & & & 0.09 \\
\hline 26 & 2 & .09 & 14 & 002 & & & & & 42 & 01 & & & -0 & 02 & -0.04 \\
\hline & & & & & & & & & & & & & & & 0.05 \\
\hline 28 & 41 & & & & & & & & & 2 & & & 04 & & -0.05 \\
\hline 2 & & & & & & & & & & & & & & & -0.09 \\
\hline 30 & 40 & & & & 01 & & & & & 01 & & & 2 & & 0.09 \\
\hline 31 & & & & & & & & & & & & & -0.01 & -0.002 & -0.04 \\
\hline 32 & 25 & & & & & & & & & 0.000 & & & & & 0.08 \\
\hline 33 & 1.21 & & & & & & & & & & & & 0.01 & 0.000 & -0.03 \\
\hline 34 & & & & & & & & & & & & & & & -0.01 \\
\hline 35 & 1.21 & & & 0.001 & & & & & 0.046 & 0.000 & 0.03 & & -0.03 & -0.003 & 0.05 \\
\hline 36 & 1.27 & & & & & & & & & & & & -0.04 & 0.003 & -0.09 \\
\hline 37 & 1.43 & & & & & & & & & 0.001 & & & & 0.004 & 0.02 \\
\hline 38 & & & & & & & & & & & & & & 0.000 & -0.04 \\
\hline 39 & 1.26 & & & & 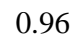 & 0 . & 1.33 & 0.01 & 0.044 & 0.000 & 8 & 0.03 & -0.07 & -0.001 & 00 \\
\hline 40 & 1.48 & & & & & & & & & & & & & & \\
\hline 41 & 1.43 & 0.07 & & 0.003 & 0.83 & & & & & & & & & & -0.07 \\
\hline $4^{7}$ & .38 & & & & & & & & & & & & 01 & 001 & -0.04 \\
\hline 43 & 1.35 & 0.02 & 0.050 & 0.001 & 0.81 & 0. & 1.37 & 0.02 & 0.051 & 0.000 & & 0.02 & -0.02 & -0.001 & 0.08 \\
\hline 44 & 1.36 & 0.04 & 0.047 & 0.003 & 0.94 & 0.04 & 1.35 & 0.02 & 0.045 & 0.001 & 0.90 & 0.03 & 0.01 & 0.002 & 0.04 \\
\hline
\end{tabular}


Table 1

Continued

\begin{tabular}{|c|c|c|c|c|c|c|c|c|c|c|c|c|c|c|c|}
\hline \multirow[t]{2}{*}{ no. } & \multicolumn{6}{|c|}{ 3D HNCO } & \multicolumn{6}{|c|}{ 2D HSQC } & \multicolumn{3}{|c|}{ HNCO-HSQC } \\
\hline & $\mathrm{T} 1$ & & $\mathrm{~T} 2$ & & $\bar{E}$ & & T1 & & $\mathrm{T} 2$ & $\sigma_{\mathrm{T} 2}$ & E & & 1 & 2 & $\Delta \mathrm{NOE}$ \\
\hline 45 & 1.44 & 06 & 048 & & 38 & & 1.37 & $\longdiv { 1 }$ & 046 & 001 & 92 & & & 0.002 & -0.04 \\
\hline 46 & 25 & & & & & & & & & & & & & & \\
\hline 47 & 27 & & & & & & & & & & & & 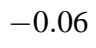 & 0.001 & -0.03 \\
\hline 48 & 16 & & & & & & & & 43 & 01 & 92 & & 00 & .001 & 0.00 \\
\hline 49 & 34 & & 62 & & & & & & & 01 & & & 0.05 & -0.006 & -0.05 \\
\hline 50 & 38 & 04 & 44 & & & & & & 0.043 & 0.000 & 90 & & 0.07 & 0.001 & 0.06 \\
\hline 51 & 32 & 03 & 046 & 1 & 87 & & 1.37 & & 0.047 & 0.001 & 0.87 & & -0.05 & -0.001 & 0.00 \\
\hline 52 & 36 & 05 & 042 & & 34 & & & & 043 & 0.000 & 89 & & 0.06 & -0.001 & -0.05 \\
\hline 53 & 41 & 07 & 042 & & & & & & 045 & 0.002 & 90 & & 0.01 & -0.003 & 0.05 \\
\hline 5 & & 03 & 045 & & 38 & & & & 0.044 & 00 & 91 & & 0.00 & 0.001 & -0.03 \\
\hline 55 & 38 & 04 & .041 & 1 & 86 & & & & 0.044 & 0.000 & 90 & & 0.00 & -0.003 & -0.04 \\
\hline 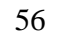 & & 06 & 046 & & & & & & 45 & 94 & & & 0 . & 0.001 & -0.02 \\
\hline 57 & 22 & 07 & .047 & 1 & 35 & & & & 0.046 & 0.000 & 79 & & -0.03 & 0.001 & 0.06 \\
\hline 5 & & 04 & 47 & & & & 1.30 & & 0.047 & 0.000 & & & & 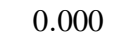 & -0.01 \\
\hline 59 & 49 & 06 & 0.047 & 3 & 3 & & & & & & & & & & \\
\hline 60 & 38 & & 65 & & & & & & 70 & 2 & 6 & & 2 & 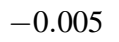 & 02 \\
\hline 61 & 1.35 & & 044 & & & & & & 0.047 & 0.001 & 38 & & -0 & -0 & 0.02 \\
\hline 62 & 31 & & 48 & & & & & & 0.048 & 00 & 36 & & -0 & & 0.03 \\
\hline 6. & 0 & & & & & & & & & & & & 0. & 0 & 0.08 \\
\hline 64 & 40 & & 43 & & & & & & 45 & 01 & 37 & & 2 & & -0.01 \\
\hline 6 & & & & & & & & & & & & & & & 0.02 \\
\hline 66 & 45 & 0.06 & 48 & & 30 & & & & 0.048 & 01 & 86 & & -0 & 00 & -0.06 \\
\hline 6 & & & & & & & & & & & & & & & 0.07 \\
\hline 68 & 39 & 0.03 & 48 & & 1 & & 45 & & 0.049 & 0.001 & 3 & & -0.06 & -0 & 0.08 \\
\hline 69 & & & & & & & & & & & & & & & 0.05 \\
\hline 7 & 9 & 0.03 & 49 & & & & 1 & & 45 & 0 & 0.79 & & -0 & T & 0.08 \\
\hline 71 & 1 & & & & & & & & & & & & & & 0.06 \\
\hline 72 & 16 & 0.07 & 044 & & م0 & & 1.43 & & 0.045 & 0.001 & 78 & & 0.03 & -0 & -0.08 \\
\hline 7 & & & & & & & & & & 0.000 & & & 0.0 & 00 & -0.06 \\
\hline 72 & 33 & 0.03 & 0.046 & 0.001 & 0.85 & & 4 & & 45 & 0.001 & 0.87 & & -0 & & -0.02 \\
\hline 75 & 50 & & 0.045 & & & & & & & & & & 0.00 & & -0.10 \\
\hline 76 & & & & & & & & & & & & & & & 0.05 \\
\hline 77 & 1.10 & 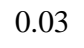 & 0.047 & & 0 & & 1.14 & 0. & 0.048 & 0.000 & 0 & & -0.04 & -0 & -0.05 \\
\hline 78 & & & & & & & & & & & & & & -0 & -0.05 \\
\hline 79 & 1.21 & 0 & 0.047 & & & & 1 & 2 & 0.047 & 00 & 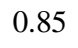 & & -0.11 & 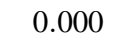 & 0.04 \\
\hline 80 & & & 0.043 & & & & & & & & & & & -0. & 0.10 \\
\hline 8 & 1.37 & 0.06 & 0.049 & 0.002 & 0.87 & & 1.39 & 4 & 0.048 & 0 & 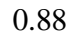 & & -0 . & 0.001 & -0.01 \\
\hline 82 & & & 0.045 & & & & 1.30 & 0.05 & 0.045 & 0.001 & 0.83 & 0.02 & -0.10 & 0.000 & 0.02 \\
\hline 83 & 1.55 & 0.13 & 0.051 & 0.001 & 0.85 & 0. & & & & & & & & & \\
\hline 8 & 1.45 & & 0.041 & & & & & & & & & & & 02 & 0.01 \\
\hline 85 & 1.21 & 0.06 & 0.050 & 0.001 & 0.86 & 0. & 1.17 & 0.02 & 0.046 & 0.001 & 0.91 & & 0.04 & 0.004 & -0.05 \\
\hline 80 & 1.44 & 0 & 044 & & & & 1. & 0.02 & 43 & & & & & 01 & -0.02 \\
\hline 87 & 1.32 & 0.03 & 0.043 & 0.001 & 0.81 & 0.03 & 1.33 & 0.01 & 0.045 & 0.000 & 0.87 & 0.02 & -0.01 & -0.002 & -0.06 \\
\hline 88 & 0.96 & 0.02 & 0.070 & 0.001 & 0.73 & 0.02 & 0.95 & 0.01 & 0.069 & 0.001 & 0.69 & 0.01 & 0.01 & 0.001 & 0.04 \\
\hline
\end{tabular}


Table 1

Continued

\begin{tabular}{|c|c|c|c|c|c|c|c|c|c|c|c|c|c|c|c|}
\hline \multirow[t]{2}{*}{ no. } & \multicolumn{6}{|c|}{ 3D HNCO } & \multicolumn{6}{|c|}{ 2D HSQC } & \multicolumn{3}{|c|}{ HNCO-HSQC } \\
\hline & $\mathrm{T} 1$ & $\sigma_{\mathrm{T} 1}$ & $\mathrm{~T} 2$ & $\sigma_{\mathrm{T} 2}$ & $\mathrm{E}$ & & $\mathrm{T} 1$ & $\sigma_{\mathrm{T} 1}$ & $\mathrm{~T} 2$ & $\sigma_{\mathrm{T} 2}$ & NOE & & $\Delta \mathrm{T} 1$ & $\mathrm{~T} 2$ & 70 \\
\hline 89 & 1.27 & & 0.045 & 0002 & 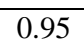 & & 1.34 & (00? & .042 & & 0.92 & & 0.07 & & 0.03 \\
\hline 90 & & & & & & & & & & & & & & & 0.03 \\
\hline 91 & 26 & & & & & & & & & & & & & & 0.0 \\
\hline 92 & & & & & & & & & & & & & & & 0.0 \\
\hline 93 & 0 & & 51 & J & & & & & & & & & -0.03 & & -0.01 \\
\hline 94 & & & & 2 & & & & & & & & 2 & 94 & 0 & -0.01 \\
\hline 95 & 29 & & 946 & 001 & 95 & & 33 & & 46 & 00 & 85 & .03 & -0.04 & 0.000 & 0.10 \\
\hline 96 & 22 & & & 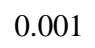 & 30 & & 25 & & 47 & & 2 & 3 & -0.03 & -0.002 & -0.02 \\
\hline 97 & 77 & & 63 & 001 & 78 & & 82 & & 63 & 00 & 0.69 & 0.02 & -0.05 & 0.000 & 0.09 \\
\hline 98 & 39 & & & 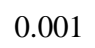 & & & 28 & & 52 & & & & .11 & & -0.05 \\
\hline 99 & 38 & & 48 & 2 & & & 41 & & 48 & & 0.89 & 0.02 & -0.03 & & 0.0 \\
\hline 100 & & & & & & & & & & & & & & & 0.09 \\
\hline & 5 & & 40 & 0 & & & & & 41 & & 0.90 & 0.02 & -0.08 & & 0.05 \\
\hline 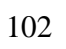 & & & & & & & & & & & & & & & 0.09 \\
\hline - & & & & 1 & & & 1 & & 50 & & 36 & 1 & -0.06 & 01 & -0.01 \\
\hline & & & & & & & & & & & & & 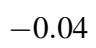 & & -0.0 \\
\hline 25 & & & & 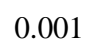 & & & & & & & 0. & & 03 & & 0.0 \\
\hline & 3 & & & & & & 27 & & & & & & 04 & & -0.09 \\
\hline 7 & & & & 0 & & & & & & & & & 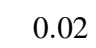 & & 0.07 \\
\hline & 8 & & & & & & 38 & & & & & & 00 & & -0.05 \\
\hline 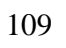 & & & & 1 & & & & & & & & & & 3 & -0.07 \\
\hline & 46 & & & 0 & 76 & & 18 & & 54 & & 1 & & .02 & & -0.05 \\
\hline 111 & & & & & & & & & & & & & & & -0.05 \\
\hline & & & & 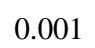 & & & 34 & & 45 & & & & 0 & & 0.1( \\
\hline & & & & & & & & & & & & & & & 0.0 \\
\hline & & & 4 & & & & 62 & & 15 & & & & -0.09 & & 0.0 \\
\hline & & & & & & & & & & & & & & & 0.0 \\
\hline & & & & & & & 1.26 & & 49 & & 075 & 003 & -0.05 & 0.002 & م \\
\hline & & & & & & & & & & & & & & & \\
\hline & & & & & & & & & & & & & & & -0.07 \\
\hline & & & & & & & & & & & & & & & \\
\hline & & & & & & & & & & & & & & & -0.01 \\
\hline - & & & & & & & & & & & & & & & 0.04 \\
\hline & & & & & & & & & & & & & & & -0.05 \\
\hline 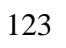 & & & & & & & & & & & & & 2 & & 0.03 \\
\hline & & & & & & & & & & & & & & & \\
\hline & & & & & & & & & & & & & & & 05 \\
\hline & & & .045 & & & & & & & & & & -0.07 & & 0.02 \\
\hline 27 & & & & & & & & & & & & & 0.06 & & 0.0 \\
\hline & & & & & & & & & & & & & .09 & & -0.0 \\
\hline & 1.27 & 0.01 & .049 & 0.001 & 0.8 & & 1.33 & & 0.050 & & 0.84 & 0.02 & -0.06 & & 0.0 \\
\hline & & & & & & & & & & & & & 0.07 & & 0.0 \\
\hline 31 & 1.47 & 0.07 & 0.047 & 0.002 & 0.88 & & 1.45 & 0.04 & 0.048 & & 0.80 & 0.05 & 0.02 & -0.001 & 0.0 \\
\hline & & & & & & & & & & & 0. & & & & -0.06 \\
\hline 133 & 1.31 & 0.02 & 0.042 & 0.001 & 0.90 & 0.02 & 1.32 & 0.02 & 0.044 & 0.000 & 0.87 & 0.02 & -0.01 & -0.002 & 0.03 \\
\hline
\end{tabular}


Table 1

Continued

\begin{tabular}{|c|c|c|c|c|c|c|c|c|c|c|c|c|c|c|c|}
\hline \multirow[t]{2}{*}{ no. } & \multicolumn{6}{|c|}{ 3D HNCO } & \multicolumn{6}{|c|}{ 2D HSQC } & \multicolumn{3}{|c|}{ HNCO-HSQC } \\
\hline & $\mathrm{T} 1$ & $\mathrm{~T} 1$ & $\mathrm{~T} 2$ & $\overline{\sigma_{\mathrm{T} 2}}$ & NOE & $\overline{\mathrm{NOE}}$ & $\mathrm{T} 1$ & $\sigma_{\mathrm{T} 1}$ & $\mathrm{~T} 2$ & $\overline{\sigma_{\mathrm{T} 2}}$ & $\mathrm{NOE}$ & $\overline{\sigma_{\mathrm{NOE}}}$ & $\Delta \mathrm{T} 1$ & $\Delta \mathrm{T} 2$ & $\Delta \mathrm{NO}$ \\
\hline 4 & 1.07 & 04 & 1 & & $\overline{70}$ & & .09 & 0.03 & 052 & & 0.73 & & .02 & 0.001 & -0.03 \\
\hline & 37 & & & & & & & & & & & & 0.0 & 0.000 & -0.0 \\
\hline 136 & 37 & 2 & 43 & 01 & 95 & & 7 & 0.02 & 46 & 01 & 0.89 & 2 & 0.00 & -0.003 & 0.06 \\
\hline 37 & 51 & 08 & 50 & 007 & 36 & & & 0.03 & 49 & 02 & 0.87 & & 0.01 & 0.001 & -0.01 \\
\hline 38 & 38 & 04 & 51 & 001 & 0.86 & & 37 & 0.02 & 050 & 001 & 0.85 & 2 & 0.01 & 0.001 & 0.01 \\
\hline 39 & 39 & 03 & 53 & 002 & 0.76 & & 6 & 0.01 & 50 & 01 & 0.80 & .03 & -0.07 & 0.003 & -0.04 \\
\hline & 25 & 01 & 49 & 0.001 & 0.79 & 3 & 26 & 0.02 & 050 & 01 & 0.75 & 0.02 & -0.01 & -0.001 & 0.04 \\
\hline 1 & 35 & 03 & 45 & 001 & 0.98 & 3 & 39 & 0.02 & 48 & 00 & 0.92 & 0.02 & -0.04 & -0.003 & 0.0 \\
\hline 12 & 48 & 02 & 51 & 001 & 0.75 & 2 & 50 & 0.02 & 050 & 00 & 0.78 & 0.02 & -0.02 & 0.001 & -0.03 \\
\hline 143 & 20 & 0.02 & 052 & 001 & 0.83 & 2 & 22 & 0.02 & 054 & 00 & 0.83 & 0.02 & -0.02 & -0.002 & 0.00 \\
\hline & 38 & 03 & 7 & 1 & 0 & & & & 18 & & 0.90 & 2 & -0 & & 0.0 \\
\hline 15 & 3 & 06 & 1 & 0 . & 0.77 & & 2 & & 55 & 00 & 0.78 & 0.03 & -0.09 & -0.004 & -0.01 \\
\hline 6 & 1 & 3 & 4 & 1 & 0 . & & & & & & 0.88 & 12 & -( & & -0.01 \\
\hline & & & & 1 & 0.70 & & & & 59 & & 0.66 & 0.01 & 0.05 & -0.003 & 0.04 \\
\hline 8 & 7 & 3 & 1 & 01 & 0.84 & & 45 & 0.01 & 51 & & 0.83 & 2 & 0.02 & & 0.01 \\
\hline & & 0.0 & & 03 & & & 46 & & & & 0.89 & 0.04 & 0.01 & 0.005 & 0.04 \\
\hline & 50 & 8 & 46 & 07 & 85 & 2 & .49 & 0.03 & 43 & & 0.82 & 55 & 0.01 & 03 & 0.03 \\
\hline & 98 & 0.01 & & 1 & & & 0 & & & & 7 & 0.01 & -0.02 & & 0.02 \\
\hline 2 & 39 & 02 & 52 & 0.001 & 0.82 & 0.02 & .42 & 0.01 & 53 & 0.000 & 0.81 & 0.01 & -0.03 & -0.001 & 0.01 \\
\hline & & & & 01 & 0 & & & 0. & & & 0 . & 3 & 0.08 & -0.004 & -0.06 \\
\hline 4 & 39 & 03 & 48 & 0.002 & 0.78 & 0.02 & 1.34 & 0.01 & 048 & 0.001 & 0.90 & 0.02 & 0.05 & 0.000 & -0.12 \\
\hline & 0 & 0.02 & 48 & 01 & & & & 0. & & & & 0.02 & -0.04 & 0 & 0.01 \\
\hline 156 & 32 & 04 & 041 & 0.001 & 0.84 & 0.04 & .35 & 0.01 & .043 & 0.000 & 0.85 & 0.03 & -0.03 & -0.002 & -0.01 \\
\hline & 27 & 00 & 46 & 0.001 & 0.8 & & 4 & 0.05 & 46 & .000 & 0.82 & 0.03 & -0.07 & 0.000 & 0.0 \\
\hline 158 & 33 & 0.04 & 47 & 0.002 & 0.86 & 2 & 41 & 0 . & 49 & 33 & 0.89 & 0.02 & -0.08 & -0.002 & -0.03 \\
\hline & 42 & 0 & 43 & .003 & 0.87 & & 7 & 0. & 42 & 1 & 0.86 & 0. & 0.05 & 0.001 & 0.0 \\
\hline 50 & 1.31 & 020 & 047 & 0.004 & 0.86 & 5 & 1.33 & 0. & 42 & 0.003 & 0.86 & 0.05 & -0.02 & 0.005 & 0.00 \\
\hline 61 & .32 & 0.0 & 51 & .000 & 0.75 & 2 & 1.34 & 0. & 52 & 0.001 & 0.82 & 0.01 & -0.02 & -0.001 & -0.0 \\
\hline 162 & 1.17 & 0.09 & 88 & 0.004 & 0.58 & 0.09 & 1.26 & 0.03 & 91 & 1 & 0.59 & 0.04 & -0.09 & -0.003 & -0.01 \\
\hline 163 & 48 & 3 & 48 & 01 & 0. & 2 & 1.48 & 0. & 50 & 00 & 0.85 & 0.02 & 0.00 & -0.002 & $-0.0^{\circ}$ \\
\hline $1 \mathrm{C}^{2}$ & 1.38 & 0.03 & 049 & 0.001 & 0.97 & & 1.42 & 0.02 & & & 0.90 & 0.02 & -0.04 & 0.001 & 0.07 \\
\hline 165 & 1.20 & 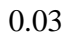 & 55 & 0.001 & 0.8 & 3 & 1.21 & 0. & 57 & 00 & 0.79 & 0.02 & -0.01 & -0.002 & 0.0 \\
\hline 166 & 1.46 & & 046 & 0.00 & & & & 0. & & & 0.89 & & 0.07 & 0.001 & $-0.0 t$ \\
\hline 167 & 1.58 & 0. & 065 & 0.004 & 0.77 & 0 & .57 & 0.03 & 68 & 02 & 0.81 & 0.05 & 0.01 & -0.003 & -0.0 \\
\hline & 1.26 & 00 & 106 & 0.009 & 0.6 & & 1.36 & 0. & 09 & & 0.63 & 0.03 & -0.10 & -0.003 & 0.0 \\
\hline & 1.43 & 0.03 & .049 & 0.001 & 0.95 & 0.02 & 1.45 & 0.01 & 0.050 & 0.001 & 0.88 & 0.02 & -0.02 & -0.001 & $0.0^{\prime}$ \\
\hline & .39 & 0.02 & 0.050 & 0.001 & 0.7 & 2 & 1.44 & 0.02 & 50 & 0.001 & 0.84 & 0.02 & -0.05 & 0.000 & -0.07 \\
\hline 171 & 1.35 & 0.0 & 0.048 & 0.003 & 0.9 & 0.05 & 1.32 & 0.0 & 0.045 & & 0.90 & 0.03 & 0.03 & 0.003 & 0.0 \\
\hline 172 & 1.28 & 0.05 & 0.049 & 0.003 & 0.87 & 0.04 & 1.30 & 0.03 & 0.045 & 0.001 & 0.86 & 0.03 & -0.02 & 0.004 & 0.0 \\
\hline
\end{tabular}

$\Delta \mathrm{T} 1, \Delta \mathrm{T} 2$, and $\Delta \mathrm{NOE}$ are the differences between $\mathrm{T} 1, \mathrm{~T} 2$, and NOE obtained from the 3D TROSY-HNCO based experiments and the values from the corresponding 2D HSQC experiments.

D Overlapped peaks in 2D HSQC. T1, T2, and NOE data for these peaks cannot be obtained from 2D HSQC experiments due to their overlapping with other peaks. Peak of no. 40 is overlapped with no. 101 and 147. Peak of no. 59 is overlapped with that of no. 49. Peak of no. 83 is overlapped with no. 148. Peak of no. 117 is overlapped with no. 132. Peak of no.124 is overlapped with no. 103 . 
Experiments relating 3D T1-HSQC-HNCO and 3D T2-HSQC-HNCO, to the corresponding 2D T1HSQC and 2D T2-HSQC were also performed using a Varian Inova $500 \mathrm{MHz}$ NMR spectrometer (data not shown here). These also showed excellent agreement between the 3D HSQC-HNCO based experiments and the corresponding 2D HSQC based experiments.

As we know, ${ }^{13} \mathrm{C}$ labeling of a protein could increases the longitudinal relaxation rate by $4 \%$ at $500 \mathrm{MHz}$ due to ${ }^{13} \mathrm{CO}_{-}{ }^{15} \mathrm{~N}$ and ${ }^{13} \mathrm{C}_{-}-{ }^{15} \mathrm{~N}$ dipole-dipole interactions [32,35]. However, the effect of chemical shift anisotropy (CSA) of ${ }^{15} \mathrm{~N}$ on ${ }^{15} \mathrm{~N}$ relaxation becomes more significant as the magnet field increases. At $750 \mathrm{MHz}$, the effect of CSA and DD $\left({ }^{15} \mathrm{~N}-{ }^{1} \mathrm{H}\right)$ are comparable. Therefore the relaxation contribution due to dipolar-dipolar interaction between ${ }^{13} \mathrm{CO} /{ }^{13} \mathrm{C} \alpha$ and ${ }^{15} \mathrm{~N}$ is less than $2 \%$ for $R_{1}$ and $1 \%$ for $R_{2}$ at $750 \mathrm{MHz}$ or higher fields. This contribution is small compared with the experimental error. In our experiment, the pulse width of $180^{\circ}$ pulse of CPMG was $80 \mu$ s although the rf power of CPMG section was reduced by $3 \mathrm{~dB}$ compared to full $\mathrm{rf}$ power in the ${ }^{15} \mathrm{~N}$ channel. The strength of rf field for CPMG was $6.25 \mathrm{kHz}$. For our tested sample, the maximum effective spectral width was only $2.2 \mathrm{kHz}$, therefore the rf power for CPMG is enough to cover the effective spectral range. In this case, the relative difference $\Delta T_{2} / T_{2} \leqslant 3 \%$ [35,37]; the heating effect was significantly reduced and the off-resonance effect is acceptable.

It is known that the 2D HSQC method is less effective for measuring the dynamics parameters of large proteins. The measurement technique for $T_{1}$ using 2D constant-time accordion NMR spectroscopy [38] reduces sensitivity because required constant-time period of $120 \mathrm{~ms}$ or $60 \mathrm{~ms}$ will cause severe signal decay. For example, for an uniformly $100 \%{ }^{15} \mathrm{~N}, 100 \%{ }^{13} \mathrm{C}$, and $70 \%{ }^{2} \mathrm{H}$-labelled trichosanthin sample $(\sim 27 \mathrm{kDa}, 1.0 \mathrm{mM})$ at $30^{\circ} \mathrm{C}$, the signal strength in $2 \mathrm{D}$ constant-time $(120 \mathrm{~ms})$ accordion spectroscopy will be only about $15 \%$ of that of a spectrum acquired by the 2D HSQC method [10]. The 3D accordion spectroscopy method [32] for measuring ${ }^{15} \mathrm{~N} T_{1}$ is not practical either because of the line broadening resulting from modulated transverse magnetization of $\mathrm{CO}$ during the period of $t_{1}$ evolution and the need for special data processing. Furthermore, accordion spectroscopy techniques are not applicable for measuring $T_{2}$ and NOE. Therefore, 2D HSQC [10] and 2D or 3D accordion spectroscopy methods are less effective for NMR dynamics studies of proteins with molecular weights higher than $30 \mathrm{kDa}$. Although, the 3D HSQC-HNCO experiments for dynamics measurement of protein are the same in spirit to those published earlier [26], there are noticeable differences in details between our experiments and the earlier ones. The major difference is that our 3D HSQC-HNCO experiments is designed to measure $T_{2}$ relaxation times instead of $T_{1 \rho}$, which are necessary in our comparison with the corresponding 3D TROSY-based experiments for dynamics measurement. We did not apply WALTZ16 in the $t_{1}$ and $T_{1}$ (or $T_{1 \rho}$ ) periods for proton decoupling and the phase cycling in our experiments is limited to two which minimizes the total experimental time whereas in the Caffrey's paper, a phase cycling of 16 is used. The sensitivity of our 3D HSQC-HNCO dynamics experiments is much higher when compared with the Caffrey's experiments because our sequence is $5.4 \mathrm{~ms}$ shorter and the PEP (Preservation of Equivalent Paths) [3,39] sequence is used before detection.

\section{Conclusions}

This work proposes 3D TROSY-HNCO and HSQC-HNCO based pulse sequences for measuring ${ }^{15} \mathrm{~N}$ $T_{1}, T_{2}$ and ${ }^{1} \mathrm{H}_{-}{ }^{15} \mathrm{~N}$ NOE. Because the number of phase cycling steps in these pulse sequences is limited to two, all experiments can be finished within an appropriate period of time. TROSY-based measurements can significantly enhance signal sensitivity in dynamics studies of large deuterated protein molecules. 
For the tested sample at $30^{\circ} \mathrm{C}$, the sensitivity of the 3D TROSY-HNCO based technique was, on the average, enhanced by $72 \%$ compared to that of the 3D HSQC-HNCO based measurements. For fully deuterated or larger proteins, the TROSY effect should be even stronger. The 3D HSQC-HNCO based measurements should be more effective with non-deuterated samples, with smaller molecular weights and seriously overlapped 2D HSQC spectra. Statistical analysis confirmed that the results from the 3D TROSY-HNCO and 3D HSQC-HNCO based experiments are in good agreement with those measured with the traditional 2D HSQC techniques. The 3D TROSY-HNCO and 3D HSQC-HNCO spectra have significantly reduced spectral overlap compared with their 2D counterparts. As overlapping of NMR peaks becomes more and more serious with increased molecular weight of the sample studied, dynamics measurements employing the 3D TROSY-HNCO or HSQC-HNCO scheme will become more important in the near future.

\section{Acknowledgement}

This work is supported by grants from the Research Grants Council of Hong Kong (HKUST6038/98M, 6199/99M and 6208/00M). The Hong Kong Biotechnology Research Institute is acknowledged for the purchase of the $750 \mathrm{MHz}$ NMR spectrometer.

\section{References}

[1] J.W. Peng and G. Wagner, Method. Enzymol. 239 (1994), 563-596.

[2] L.E. Kay, D.A. Torchia and A. Bax, Biochem. 28 (1989), 8972-8979.

[3] L.E. Kay, L.K. Nicholson, F. Delaglio, A. Bax and D.A. Torchia, J. Magn. Reson. 97 (1992), 359-375.

[4] M. Karplus and G.A. Petsko, Nature 347 (1990), 631-639.

[5] M.V. Milburn, L. Tong, A.M. De Vos, A. Brunger, Z. Yamaizumi, S. Nishimura and S. Kim, Science 247 (1990), $939-945$.

[6] G. Barbato, M. Ikura, L.E. Kay, R.W. Pastor and A. Bax, Biochemistry 31 (1992), 5269-5278.

[7] A. Amadei, A.B.M. Linssen and H.J.C. Berendsen, Proteins 17 (1993), 412-425.

[8] V.A. Feher and J. Cavanagh, Nature 400 (1999), 289-293.

[9] E.D. Alba and N. Tjandra, J. Magn. Reson. 144 (2000), 367-371.

[10] N.A. Farrow, R. Muhandiram, A.U. Singer, S.M. Pascal, C.M. Kay, G. Gish, S.E. Shoelson, T. Pawson, J.D. Forman-Kay and L.E. Kay, Biochemistry 33 (1994), 5984-6003.

[11] G. Lipari and A. Szabo, J. Am. Chem. Soc. 104 (1982) 4546-4559.

[12] G. Lipari and A. Szabo, J. Am. Chem. Soc. 104 (1982), 4559-4570.

[13] N. Tjandra, S. Grzesiek and A. Bax, J. Am. Chem. Soc. 118 (1996), 6264-6272.

[14] N. Tjandra and A. Bax, Science 278 (1997),1111-1114.

[15] G.M. Clore, A.M. Gronenborn and A. Bax, J. Magn. Reson. 133 (1998), 216-221.

[16] K. Pervushin, R. Riek, G. Wider and K. Wüthrich, Proc. Natl. Acad. Sci. USA 94 (1997), 12366-12371.

[17] K. Pervushin, R. Riek, G. Wider and K. Wüthrich, J. Am. Chem. Soc. 120 (1998), 6394-6400.

[18] M. Salzmann, K. Pervushin, G. Wider, H. Senn and K. Wüthrich, Proc. Natl. Acad. Sci. USA 95 (1998), $13585-13590$.

[19] M. Salzmann, G. Wider, K. Pervushin, H. Senn and K. Wüthrich, J. Am. Chem. Soc. 121 (1999), 844-848.

[20] M. Salzmann, K. Pervushin, G. Wider, H. Senn and K. Wüthrich, J. Biomol. NMR 14 (1999), 85-88.

[21] G. Zhu, X.M. Kong, X.Z. Yan and K.H. Sze, Angew. Chem. Int. Ed. Engl. 37 (1998), 2859-2861.

[22] D. Yang and L.E. Kay, J. Biomol. NMR 13 (1999), 3-10.

[23] G. Zhu, Y. Xia, L.K. Nicholson and K.H. Sze, J. Magn. Reson. 143 (2000), 423-426.

[24] J. Cavanagh, W.J. Fairbrother, A.G. Palmer III and N.J. Skelton, Protein NMR Spectroscopy, Principles and Practice, Academic Press, 1995.

[25] V. Sklenar, D. Torchia and A. Bax, J. Magn. Reson. 73 (1987), 375-379.

[26] M. Caffrey, J. Kaufman, S.J. Stahl, W. Wingfield, A. Gronenborn and G.M. Clore, J. Magn. Reson. 135 (1998), $368-372$.

[27] D. Marion, M. Ikura, R. Tschudin and A. Bax, J. Magn. Reson. 85 (1989), 393-399.

[28] H.Y. Carr and E.M. Purcell, Phys. Rev. 4 (1954), 630.

[29] S. Meiboom and D. Gill, Rev. Sci. Instrum. 29 (1958), 688. 
[30] F. Delaglio, S. Grzesiek, G.W. Vuister, G. Zhu, J. Pfeifer and A. Bax, J. Biomol. NMR 6 (1995), 277-293.

[31] Y. Xia, K.H. Sze and G. Zhu, J. Biomol. NMR 18 (2000), 261-268.

[32] P.A. Carr, D.A. Fearing and A.G. Palmer III, J. Magn. Reson. 132 (1998), 25-33.

[33] W.H. Press, S.A. Teukilsky, W.T. Vettering and B.P. Flannery, Numerical Recipes in C, 2nd edn, Cambridge Univ. Press, Cambridge, UK, 1992.

[34] R.R. Sokal and F.J. Rohlf, Biometry: The Principles and Practice of Statistics in Biological Research, 2nd edn, Freeman, New York, 1995.

[35] S.F. Lienin, T. Bremi, B. Brutscher, R. Brüschweller and R.R. Ernst, J. Am. Chem. Soc. 120 (1998), 9870-9879.

[36] D.M. Korzhnev, E.V. Tischenko, A.S. Arsenoev, J. Biomol. NMR 17 (2000), 231-237.

[37] A. Ross, M. Czisch and G.C. King, J. Magn. Reson. 124 (1997), 355-365.

[38] A.M. Mandel and A.G. Palmer III, J. Magn. Reson. A110 (1994), 62-72.

[39] A.G. Palmer, J. Cavanagh, P.E. Wright and M. Rance, J. Magn. Reson. 93 (1991), 151-170.

[40] S. Smallcombe, J. Am. Chem. Soc. 115 (1993), 44776.

[41] J.L. Markley, W.J. Horsley and M.P. Klein, J. Chem. Phys. 55 (1971), 3604. 


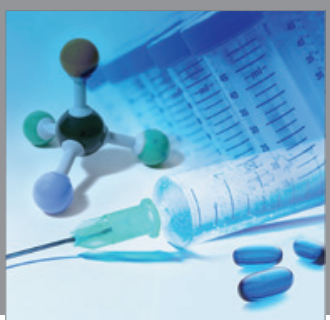

International Journal of

Medicinal Chemistry

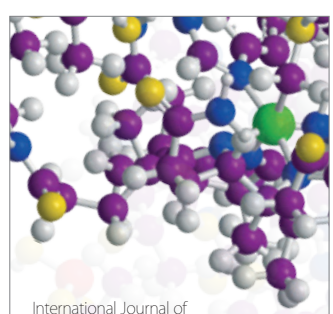

Carbohydrate Chemistry

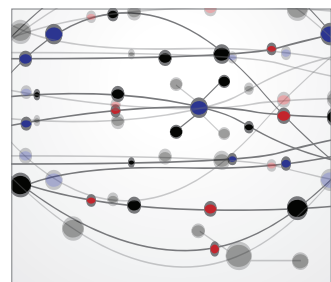

The Scientific World Journal
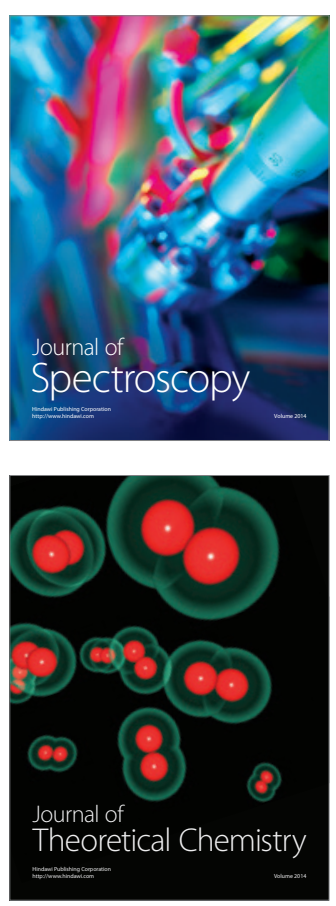
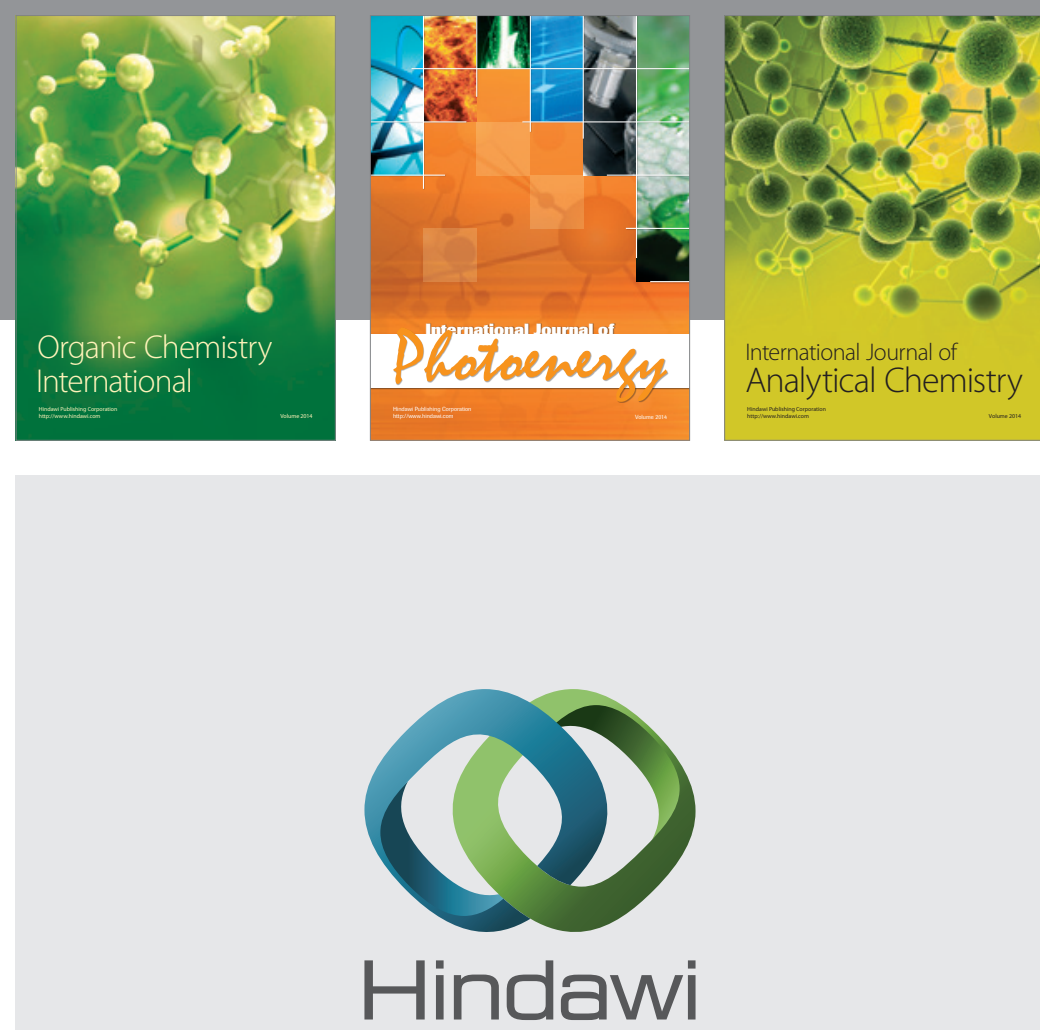

Submit your manuscripts at

http://www.hindawi.com
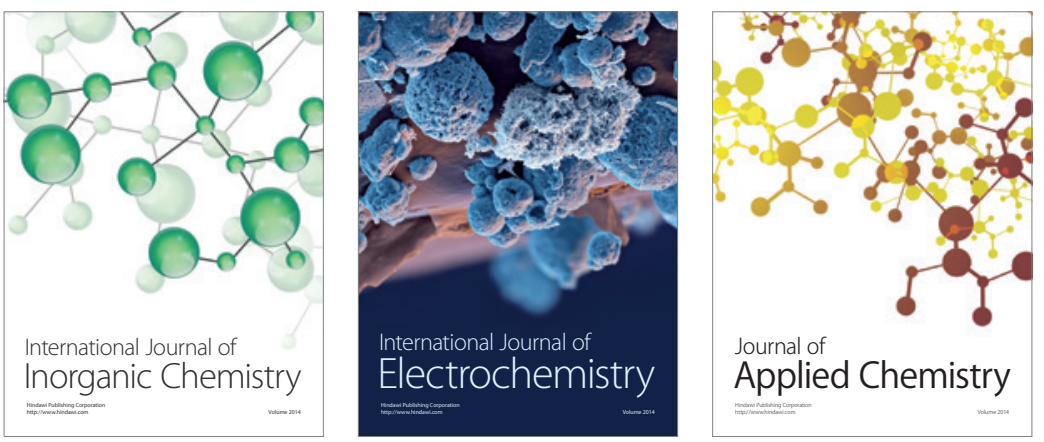

Journal of

Applied Chemistry
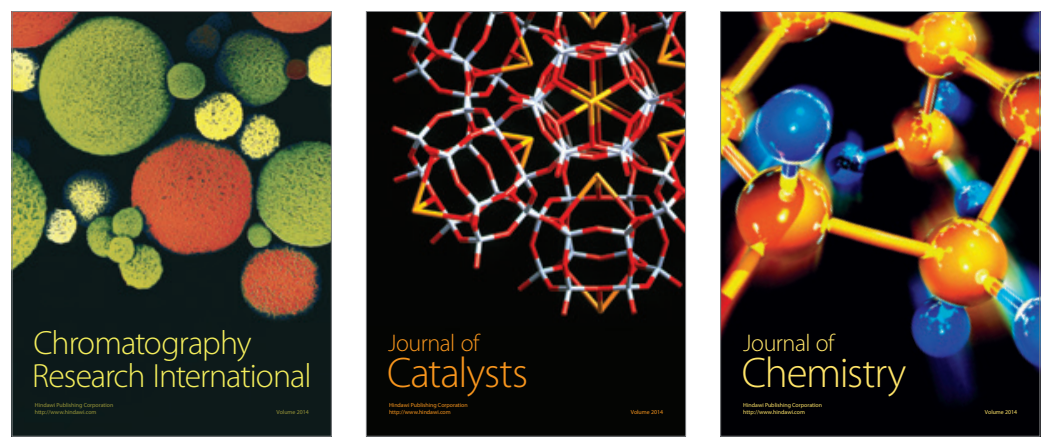
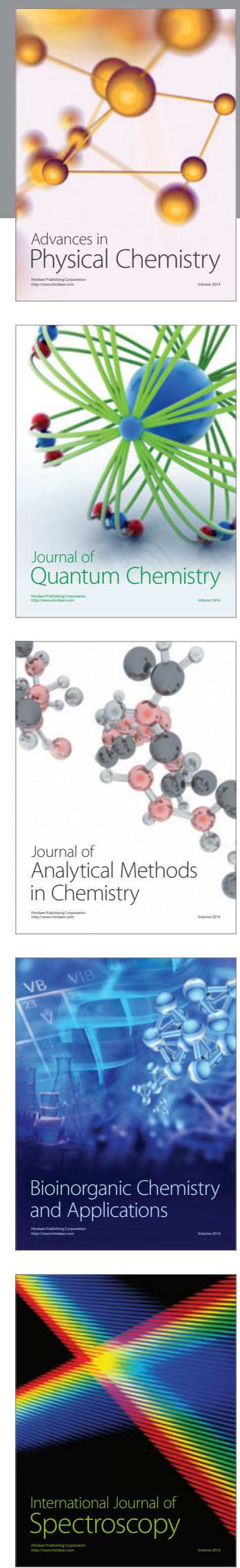